Revista Brasil. Bot., V.25, n.1, p.1-9, mar. 2002

\title{
Aplicações taxonômicas da anatomia foliar das espécies brasileiras de Hypolytrum Rich. (Cyperaceae) ${ }^{1}$
}

\author{
MARCCUS V. ALVES ${ }^{2,6}$, MARIA E.M. ESTELITA ${ }^{3}$, \\ MARIA G.L. WANDERLEY ${ }^{4}$ e WILLIAM W. THOMAS ${ }^{5}$
}

(recebido: 26 de setembro de 2000; aceito: 13 de junho de 2001)

\begin{abstract}
Taxonomic applications of leaf anatomy of the Brazilian species of Hypolytrum Rich. (Cyperaceae)). Hypolytrum Rich. (subfamily Mapanioideae) has a pantropical distribution being represented in the Neotropics by 16-21 species, most of them growing in several Brazilian ecosystems. Informations from foliar anatomy was analysed for 10 species of the genus. The most useful characters detected in Hypolytrum species studied here are: the shape of the leaves in cross section, the occurrence of granules (probably formed by silica) on the epidermal cells; features of the cuticle, the hypoderm and the aerenchymatous parenchyma; the number of layers and origin (hypodermal and epidermal) of bulliform cells; the presence of papillae on the abaxial face of the epidermis; and occurence of radiate parenchyma on the smaller bundles. Studies of foliar anatomy showed to be useful in generic and specific delimitation but do not support the taxonomic sections established.

RESUMO - (Aplicações taxonômicas da anatomia foliar das espécies brasileiras de Hypolytrum Rich. (Cyperaceae)). Hypolytrum Rich. (subfamília Mapanioideae) tem distribuição pantropical e está representado por 16-21 espécies na região Neotropical, das quais grande parte ocorre no Brasil habitando diferentes ecossistemas. São apresentados dados de anatomia foliar com maior relevância taxonômica para 10 espécies do gênero. Entre eles, destacam-se: formato da folha em secção transversal; presença de grânulos, provavelmente de sílica, em células epidérmicas; aspectos da cutícula, da hipoderme e do parênquima lacunoso; número de camadas e origem (hipodérmica e epidérmica) das células buliformes; presença de células epidérmicas papilosas; e ocorrência de parênquima radiado nos feixes menores. Os estudos de anatomia foliar mostram-se relevantes na delimitação genérica e específica, porém não apoiam as secções taxonômicas estabelecidas.
\end{abstract}

Key words - Hypolytrum, Mapania, Cyperaceae, foliar anatomy, taxonomy

\section{Introdução}

O gênero Hypolytrum Rich. é representado por cerca de 40 espécies, das quais 16-21 ocorrem na região Neotropical (Koyama 1970). No Brasil é encontrado em diferentes ecossistemas: Florestas Amazônica e Atlântica, Cerrado, Campo Rupestre e Restinga. Caracteriza-se pela forte redução das unidades florais e presença de duas, raro três, brácteas florais. Em comum com os demais gêneros da subfamília Mapanioideae (Goetghebeur 1998), apresenta os espicóides (ou pseudantos) reunidos em espigas

1. Parte da Tese de Doutorado de M.V. Alves, vinculada ao Programa de Pós-graduação em Botânica da Universidade de São Paulo.

2. Universidade Federal de Pernambuco, Departamento de Botânica. Av. Moraes Rego s/n, CDU, 50670-901 Recife, PE, Brasil.

3. Universidade de São Paulo, Departamento de Botânica. Rua do Matão, Trav. 14, CDU, 05508-900 São Paulo, SP, Brasil.

4. Instituto de Botânica, Herbário. Caixa Postal 4005, 01061-970 São Paulo, SP, Brasil.

5. The New York Botanical Garden, Herbarium. Bronx, 10458-5126 New York, NY, EUA.

6. Autor para correspondência: marccusalwes@yahoo.com.br
(Simpson 1992). Koyama (1970) enquadrou as espécies sul-americanas em quatro secções com base em caracteres da morfologia externa, entre eles a posição do escapo (central ou lateral), a ausência de folhas basais e folhas com pseudopecíolo.

A grande semelhança entre as espécies e a carência de caracteres diagnósticos de fácil visualização na morfologia externa tornam a anatomia foliar de Hypolytrum uma possível ferramenta para melhor definição dos taxa, fornecendo subsídios ao entendimento de suas relações filogenéticas.

Estudos de anatomia com enfoque taxonômico em Cyperaceae são comuns e em geral revelam bons resultados para a separação das espécies (Plowman 1906, Metcalfe 1969, Shepherd 1976). Pfeiffer (1927) e Metcalfe (1971) indicaram perfis anatômicos, ainda que bastante generalizados, de diversos gêneros da família.

O presente trabalho tem como proposta delinear o padrão da anatomia foliar de espécies brasileiras de Hypolytrum criando parâmetros que sirvam de subsídios à taxonomia, além de acrescentar informações com relação aos caracteres adaptativos detectados. 
M.V. Alves et al.: Anatomia foliar de Hypolytrum

\section{Material e métodos}

Os materiais empregados encontram-se depositados em herbários, cujas siglas seguem Holmgren et al. (1990).

Hypolytrum bullatum C.B. Clarke - BAHIA: Ilhéus, 30-I-2000, M. Alves et al. 1866 (CEPEC, NY, SP, UFP). PERnAMBUCO: São Vicente Ferrer, 6-XI-1999, M. Alves et al. 1667 (NY, SP, UFP). Hypolytrum glaziovii Boeck. - Rio DE JANEIRO: Rio de Janeiro, 12-IV-2000, M. Alves 1927 (SP, UFP). Hypolytrum longifolium (Rich.) Nees - Amazonas: Rio Preto da Eva, 14-XI-1999, $M$. Alves \& A. Amorim 1677 (NY, SI, SP, UFP). Hypolytrum pulchrum (Rudge) H. Pfeiff. - BAHIA: Maraú, 1-II-2000, M. Alves et al. 1893 (CEPEC, NY, SI, SP, UFP). Hypolytrum schraderianum Nees - Amazonas: Manaus, 17-XI-1999, M. Alves \& A. Amorim 1688 (INPA, NY, SP, UFP). SÃo Paulo: Peruíbe, 6-I-2000, M. Alves et al. 1750 (NY, SP, UFP). Hypolytrum sp. nov. - BaHia: Serra Grande, 3/2/2000, M. Alves et al. 1915 (CEPEC, NY, UFP); Uruçuca, Serra do Conduru, 4-VI-2000, M. Alves et al. 1960 (CEPEC, NY, SP. UFP). Hypolytrum sphaerostachyum Boeck. - Rondonia: Porto Velho, 8-IX-1923, J. Kuhlmann 381 (UB). Hypolytrum stemonifolium T. Koyama - AmAzonAs: Itapiranga, 21-VII-1979, C. Ferreira et al. 648 (INPA). Hypolytrum rigens Nees - BAHIA: Ibicoara, 27-I-2000, M. Alves et al. 1831 (CEPEC, NY, SP, UFP); M. Alves et al. 1836 (CEPEC, NY, SP, UFP). Hypolytrum verticillatum T. Koyama - EsPírito SANTO: Guarapari, 13-II-2000, M. Alves et al. 1916 (NY, VIES, UFP).

Como elemento de comparação adotou-se o gênero indicado por Simpson (1992) como filogeneticamente mais relacionado a Hypolytrum. Foram, então, analisadas folhas e ferófilos adultos de Mapania pycnocephala (Benth.) Benth. - Amazonas: Manaus, M. Alves \& A. Amorim 1691 (INPA, SP, UFP) e de Mapania sylvatica Aubl. - Amazonas: Manaus, $M$. Alves \& A. Amorim 1689 (INPA).

Porções da região mediana de folhas e de ferófilos foliares adultos das 10 espécies ocorrentes em diferentes ecossistemas foram fixados em FAA 50\% (Sass 1851) e, posteriormente, estocados em álcool 70\% (Johansen 1940). Quando da ausência de material fresco foram empregadas amostras provenientes de material herborizado devidamente reidratadas.

Foram realizados cortes à mão livre com auxílio de lâmina de barbear. As secções transversais (ST) obtidas foram diafanizadas em hipoclorito de sódio a $50 \%$ e submetidas ao processo de dupla coloração com safranina e azul de Astra 9:1 (modificado de Bukatsch 1972 apud Kraus \& Arduin 1997). Para epiderme, em vista frontal (VF), foi utilizado o tratamento modificado de Franklin (1945 apud Kraus \& Arduin 1997). Lâminas semi-permanentes e permanentes foram montadas em glicerina $50 \%$ e bálsamo do Canadá, respectivamente. Amido foi identificado pela solução de lugol e cloreto de zinco iodado, lignina pela solução de floroglucinol, substâncias graxas pelo sudan IV e sílica pelo fenol (Johansen 1940). O teste para compostos fenólicos foi realizado com cloreto férrico (Johansen 1940 apud Kraus \& Arduin 1997).

A tipologia foliar em ST segue o proposto por Metcalfe (1971) para a família Cyperaceae e para o formato dos feixes vasculares foi adotada a classificação de Cheadle \& Uhl (1948).

A terminologia utilizada seguiu Metcalfe (1971).

Fotomicrografias foram obtidas utilizando-se câmara Olympus C-35AD, adaptada a um fotomicroscópio Olympus Vanox e as medidas com auxílio do programa KS100 acoplado ao microscópio Zeiss.

\section{Resultados}

Aspectos morfo-anatômicos de folhas de 10 espécies de Hypolytrum são mostradas nas figuras 1-18. Nesse gênero, as folhas e os ferófilos foliares são lineares a oblongo-lanceolados; sésseis ou pseudopeciolados. Ambos são glabros, podendo apresentar "prickles" (tricomas tectores) ao longo das margens, da nervura central e das costelas laterais, na face abaxial. As folhas e ferófilos são hipostomáticos em sua maioria, com ampla variabilidade na freqüência estomática entre as espécies $\left(H\right.$. pulchrum $-\mathrm{x}=57,5$ est. $\mathrm{mm}^{-2} ; H$. stemonifolium $-\mathrm{x}=15,7$ est. $\left.\mathrm{mm}^{-2}\right)$. No entanto, $H$. sphaerostachyum é anfistomática e $H$. schraderianum o pode ser eventualmente. Os estômatos são paracíticos e localizam-se tanto no nível das demais células epidérmicas ( $H$. bullatum, $H$. pulchrum, $H$. schraderianum e $H$. sphaerostachyum) (figura 2) quanto em reduzidas depressões (H. rigens) ou em elevações (H. glaziovii, $H$. longifolium, $H$. sp., stemonifolium e $H$. verticillatum) (figura 3; tabela 2).

Revestindo a epiderme pode ser observada cutícula lisa ( $H$. bullatum, $H$. longifolium, schraderianum, $H$. sp. nov. e $H$. sphaerostachyum) ou estriada ( $H$. glaziovii, $H$. pulchrum, $H$. stemonifolium, $H$. rigens, $H$. verticillatum). Em VF, as células epidérmicas, em ambas as faces, são hexagonais a retangulares e apresentam paredes retilíneas (H. pulchrum, $H$. schraderianum, Hypolytrum sp. e H. sphaerostachyum) (figura 4) ou sinuosas (H. bullatum, $H$. glaziovii, $H$. longifolium, $H$. stemonifolium, $H$. rigens, $H$. verticillatum) (figura 5). Em ST, são encontradas espécies com a face abaxial plana (figura 2) ou ondulada (unicamente em $H$. bullatum) (figura 3) podendo as células epidérmicas serem papilosas $(H$. glaziovii, $H$. longifolium, $H$. sp. nov., $H$. sphaerostachyum, $H$. stemonifolium, $H$. verticillatum) (figuras $6,8,13$ ) ou não papilosas (H. bullatum, H. glaziovii, H. pulchrum, H. schraderianum, $H$. rigens) (figura 14). Podem ser encontradas células epidérmicas papilosas na face adaxial em $H$. longifolium, Hypolytrum sp. nov., $H$. sphaerostachyum e $H$. verticillatum. Grânulos translúcidos, provavelmente de sílica, foram evidenciados nas células epidérmicas de $H$. schraderianum, $H$. 

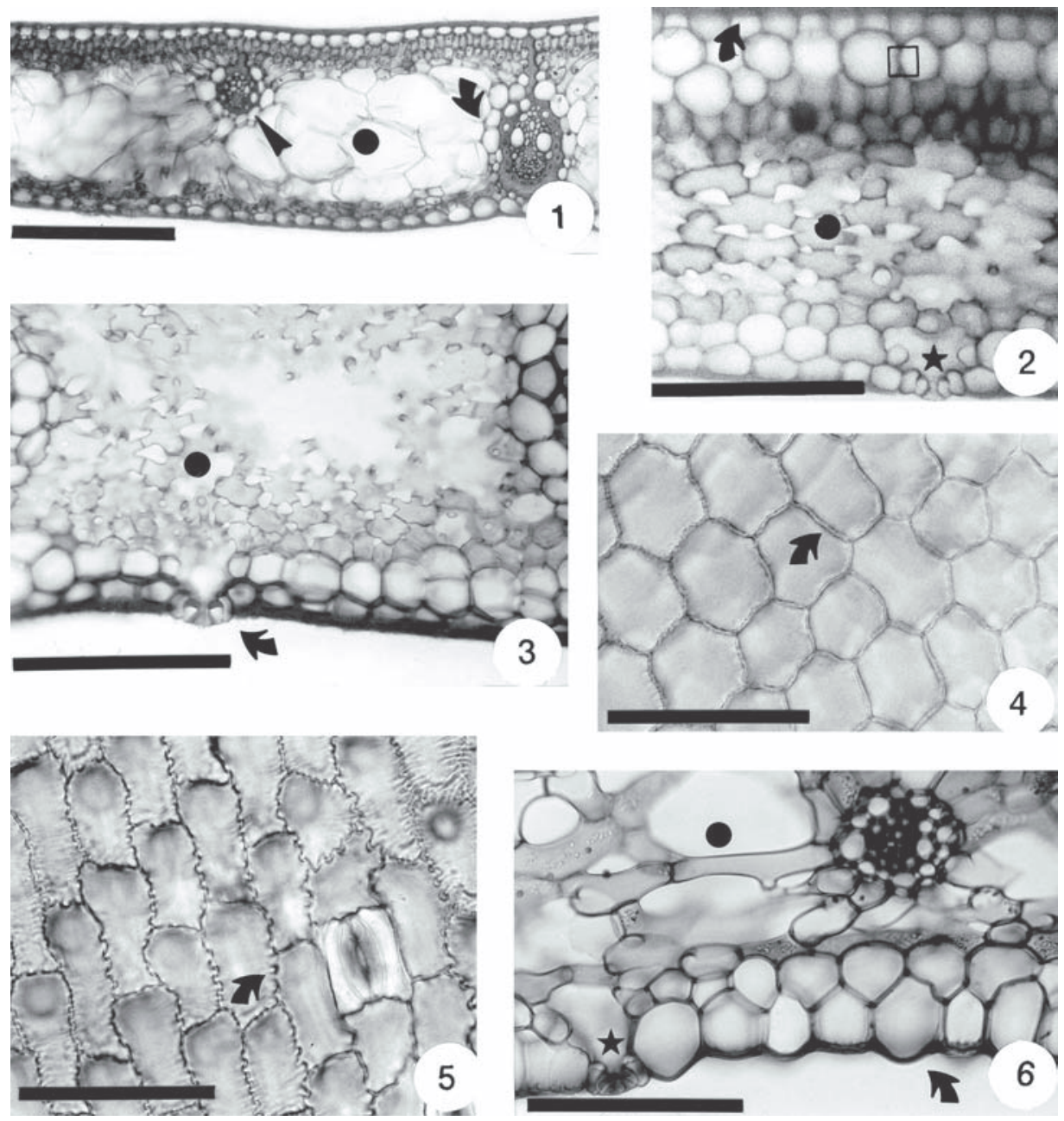

Figuras 1-3 e 6. Mesofilo em secção transversal. Figuras 4-5, epiderme em visão frontal. 1. M. pycnocephala. Epiderme de contorno retilíneo, feixes vasculares em dois níveis $(\rightarrow)$ e parênquima aqǘfero $(\bullet)$. 2. H. schraderianum. Epiderme de contorno retilíneo $(\rightarrow)$, estômatos no nível das demais células epidérmicas $(\star)$, hipoderme contínua $(\square)$ e parênquima lacunoso $(\bullet)$. 3. H. verticillatum. Estômato em reduzida elevação $(\rightarrow)$ e parênquima lacunoso $(\bullet)$. 4. H. glaziovii. Face adaxial evidenciando células hexagonais com paredes retilíneas $(\rightarrow)$. 5. H. stemonifolium. Face abaxial evidenciando células papilosas retangulares com paredes sinuosas $(\rightarrow) \mathrm{e}$ estômatos paracíticos. 6. Hypolytrum sp. nov. Células epidérmicas papilosas $(\rightarrow)$, estômatos em reduzida elevação ( $\star$ ) e parênquima lacunoso muito conspícuo $(\bullet)$. Escala $=30 \mu \mathrm{m}$ para fig. $1 ; 10 \mu \mathrm{m}$ para fig. $2,3,6 ; 20 \mu \mathrm{m}$ para fig. 4,5 .

pulchrum e Hypolytrum sp. nov. A hipoderme está presente em uma ou duas, raro três camadas $(H$. pulchrum, $H$. rigens) (figuras 7,10 ) em ambas as faces, de forma contínua ( $H$. pulchrum, H. schraderianum, Hypolytrum sp. nov., H. stemonifolium) (figuras 2, 10) ou descontínua ( $H$. bullatum, $H$. longifolium, $H$. rigens, $H$. sphaerostachyum, $H$. verticillatum) (figuras 7,9). Em geral, a descontinuidade da hipoderme deve-se à presença de esclerênquima com diferentes formatos, como em $H$. rigens (figura 11), mas também pode estar interrompida pelo parênquima paliçádico no caso de $H$. bullatum e $H$. sphaerostachyum (figuras 9, 12). Na altura da nervura central ocorrem células buliformes em uma a três camadas (múltipla) sobrepostas, com provável origem hipodérmica, epidérmica ou ambas. Em $H$. longifolium, $H$. rigens e $H$. sphaerostachyum está presente apenas uma camada de células buliformes (figuras 13, 14; tabela 2).

As folhas, em ST, são dorsiventrais e do tipo "W" invertido (H. bullatum, H. glaziovii, H. longifolium, $H$. schraderianum, Hypolytrum sp. nov., $H$. sphaerostachyum, $H$. stemonifolium, $H$. verticillatum) ou "V" expandido, podendo apresentar reentrância $(H$. pulchrum) ou não (H. rigens, $H$. sphaerostachyum). $\mathrm{Na}$ lâmina foliar podem ser encontrados de 24 a 128 feixes vasculares distribuídos no mesmo nível do mesofilo (figuras 6, 7, 11). Os feixes vasculares são ovados ou circulares do tipo III e circundados por fibras 
Tabela 1. Caracteres diferenciais de anatomia foliar entre Hypolytrum Rich. e Mapania Aubl.

\begin{tabular}{|c|c|c|}
\hline \multirow[t]{2}{*}{ Caracteres } & \multicolumn{2}{|c|}{ Gêneros } \\
\hline & Hypolytrum & Mapania \\
\hline Células epidérmicas em VF & hexagonais a retangulares & retangulares \\
\hline Corpos silicosos & ausentes & presentes \\
\hline Grânulos (provavelmente de sílica) & presentes & ausentes \\
\hline Costelas laterais & duas & nenhuma \\
\hline Parênquima translúcido nas costelas & presente & ausente \\
\hline Hipoderme & presente & ausente \\
\hline Posição dos feixes vasculares no mesofilo & um nível & dois níveis \\
\hline Parênquima aqüífero & ausente & presente \\
\hline
\end{tabular}
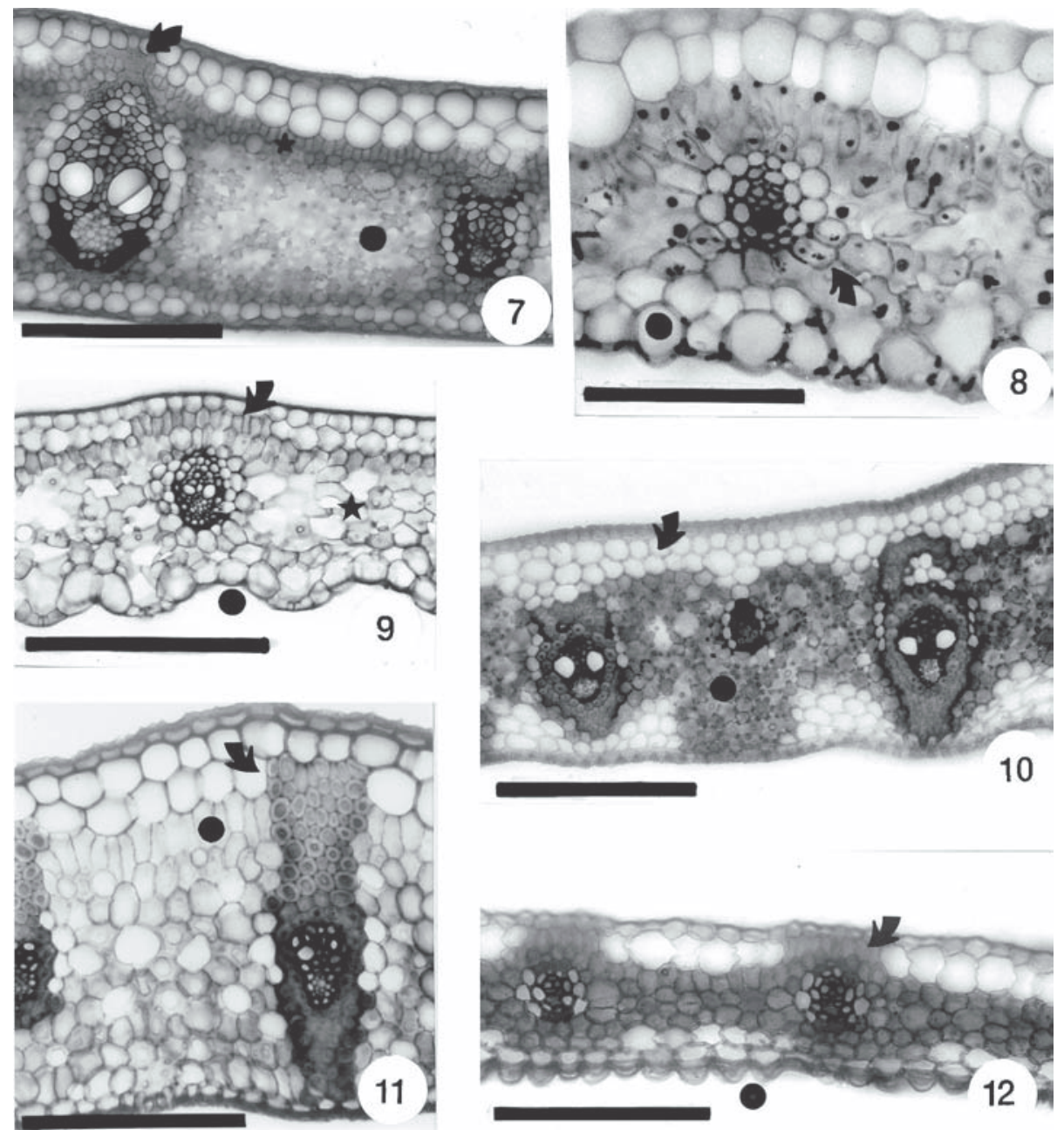

Figuras 7-12. Mesofilo em secção transversal. 7. H. verticillatum. Hipoderme descontínua $(\rightarrow)$, parênquima paliçádico $(\star)$ e parênquima lacunoso $(\bullet)$. 8. H. longifolium. Célula epidérmica papilosa $(\bullet)$ e parênquima clorofiliano radiado $(\rightarrow)$. 9. H. bullatum.Face abaxial ondulada $(\bullet)$, hipoderme descontínua $(\rightarrow)$ e parênquima lacunoso $(\star)$. 10. H. pulchrum. Hipoderme (múltipla) contínua $(\rightarrow)$ e parênquima lacunoso pouco conspícuo $(\bullet)$. 11. H. rigens. Hipoderme parcialmente descontínua $(\rightarrow)$ e parênquima paliçádico $(\bullet)$. 12. H. sphaerostachyum. Células epidérmicas papilosas $(\bullet)$ e hipoderme descontínua $(\rightarrow)$. Escala $=20 \mu \mathrm{m}$ para fig. $7,9,10 ; 10 \mu \mathrm{m}$ para fig. $8,11,12$. 
possivelmente pericíclicas e pela endoderme, em geral espessada (figuras 7, 15). As duas costelas laterais apresentam feixes vasculares semelhantes aos encontrados na nervura central, porém associados a um tecido parenquimático formado por células translúcidas circundadas total ou parcialmente por fibras (figuras 16, 17). As anastomoses vasculares são comuns às espécies estudadas. Parte do mesofilo é constituída por parênquima clorofiliano do tipo paliçádico que tende a lacunoso (esponjoso) e contém idioblastos taniníferos. O parênquima lacunoso formado por células braciformes, pode ser representado por aerênquima que, quando presente, é bastante variável entre os taxa, podendo ser pouco conspícuo (H. pulchrum) (figura 10), conspícuo (H. bullatum, $H$. glaziovii, $H$. schraderianum, $H$. verticillatum) (figura 13) ou muito conspícuo (Hypolytrum sp. nov.) (figuras 6, 15). Em algumas espécies, parte das células do parênquima clorofiliano tende à organização em paliçada (uma camada, raramente duas a três camadas, no caso de $H$. schraderianum) (figura 7) ou são indiferenciadas $(H$. pulchrum, Hypolytrum sp. nov.) (figura 10). Em $H$. bullatum, $H$. longifolium e $H$. sphaerostachyum o parênquima clorofiliano apresenta distribuição radiada em torno dos feixes vasculares de menor calibre formando, juntamente com o conjunto de bainhas, uma estrutura parecida com Kranz (figura 8; tabela 2).

O bordo foliar pode ser desprovido de fibras $(H$. schraderianum, $H$. sp. nov., $H$. sphaerostachyum, $H$. verticillatum) ou apresentá-las eventualmente em pequenos grupos. Em H. verticillatum e Hypolytrum sp. nov. o bordo é involuto (figura 18), em $H$. schraderianum é levemente revoluto, enquanto que nos demais apresenta-se truncado (tabela 2).

Ambas as espécies estudadas de Mapania (M. pycnocephala e $M$. sylvatica) apresentam lâmina foliar em ST do tipo "V" expandido, não apresentando, portanto, costelas laterais. São hipostomáticas, apresentam em VF células epidérmicas com tendência retangular e em ST epiderme retilínea e células epidérmicas não papilosas com paredes retilíneas, além da presença de corpos silicosos em forma de "pontes" depositados na parede periclinal externa. Células buliformes distribuídas em duas a três camadas, de origem epidérmica e hipodérmica, são observadas na nervura central. $\mathrm{O}$ mesofilo contém de uma a duas camadas de parênquima paliçádico, não sendo observada hipoderme diferenciada entre as espécies estudadas. Os feixes vasculares estão dispostos em dois níveis ao longo do mesofilo e são intercalados por parênquima aqüífero (figura 1; tabela 1). O bordo varia de truncado a levemente revoluto.

Chave de identificação das espécies brasileiras de Hypolytrum Rich.

1. Secção transversal (ST) da folha em "V" expandido (com ou sem reentrância)

2. Presença de parênquima com distribuição radiada nos feixes vasculares de menor calibre H. sphaerostachyum

2. Ausência de parênquima radiado nos feixes vasculares de menor calibre

3. Presença de grânulos nas células epidérmicas da face abaxial, parênquima lacunoso pouco conspícuo, parênquima paliçádico indiferenciado H. pulchrum

3. Ausência de grânulos nas células epidérmicas da face abaxial, parênquima lacunoso ausente, parênquima paliçádico em uma camada H. rigens

1. Secção transversal (ST) da folha em "W" invertido

4. Presença de parênquima radiado nos feixes vasculares de menor calibre

5. Face abaxial ondulada, parênquima lacunoso conspícuo H. bullatum

5. Face abaxial plana, parênquima lacunoso incospícuo H. longifolium

4. Ausência de parênquima radiado nos feixes vasculares de menor calibre

6. Cutícula lisa, parede das células epidérmicas em VF retilíneas, grânulos presentes nas células epidérmicas da face abaxial

7. Estômatos em elevações em relação às células epidérmicas, parênquima lacunoso muito conspícuo, parênquima paliçádico indiferenciado Hypolytrum sp. nov.

7. Estômatos no mesmo nível das células epidérmicas parênquima lacunoso conspícuo, parênquima paliçádico em duas a três camadas H. schraderianum

6. Cutícula estriada, parede das células epidérmicas em VF sinuosas, grânulos ausentes nas células epidérmicas da face abaxial 
8. Parênquima lacunoso ausente, células buliformes em uma camada H. stemonifolium

8. Parênquima lacunoso conspícuo, células buliformes em duas a três camadas

9. Bordo da lâmina truncado em ST H. glaziovii

9. Bordo da lâmina levemente involuto em ST H. verticillatum

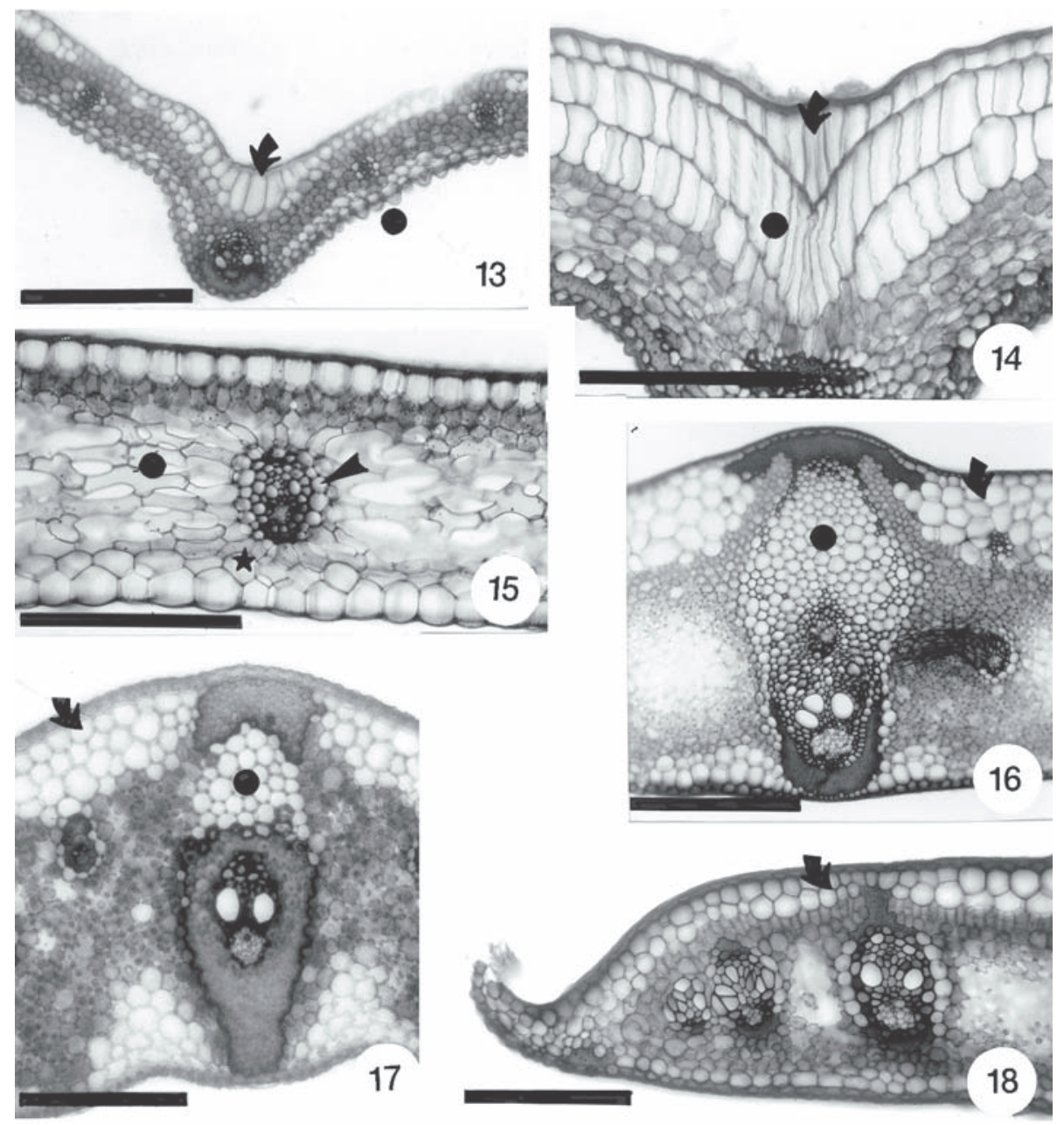

Figuras 13-18. Secções transversais da lâmina foliar. 13. H. sphaerostachyum. Células epidérmicas buliformes $(\rightarrow)$ e células epidérmicas papilosas $(\bullet)$. 14. H. schraderianum. Nervura central evidenciando células buliformes de origem hipodérmica $(\bullet)$ e epidérmica $(\rightarrow)$. 15. Hypolytrum sp. nov. Hipoderme contínua na face abaxial $(\star)$, feixes vasculares circulares $(\rightarrow)$ e parênquima lacunoso muito conspícuo $(\bullet)$. 16. H. verticillatum. Costela lateral evidenciando parênquima translúcido $(\bullet)$, hipoderme (múltipla) descontínua $(\rightarrow)$. 17. H. pulchrum. Costela lateral evidenciando hipoderme descontínua $(\rightarrow)$ e parênquima translúcido $(\bullet)$. 18. H. verticillatum. Hipoderme (múltipla) parcialmente descontínua $(\rightarrow$ ). Escala $=30 \mu \mathrm{m}$ para fig. 13, 16, 17, 18; $10 \mu \mathrm{m}$ para fig. 14, 15 .

\section{Discussão}

As similaridades na anatomia foliar entre os representantes da tribo Mapanieae, à qual pertencem Hypolytrum e Mapania, foram ressaltadas anteriormente por Koyama (1966). Metcalfe (1971) destacou ainda que, entre os representantes destes grupos, o mesofilo pode apresentar-se claramente diferenciado em parênquima paliçádico, lacunoso e aqüífero, caracterizando o padrão mais derivado nas
Cyperaceae. Esta tipologia pode ser encontrada em parte das espécies aqui tratadas.

Entre os gêneros da subfamília Mapanioideae, Hypolytrum e Exocarya, apesar de distintos na morfologia externa, revelam fortes semelhanças na anatomia foliar, diferindo fundamentalmente pela presença de hipoderme em Hypolytrum e ausência em Exocarya (Metcalfe 1971).

Mapania, considerado por Simpson (1992) como o gênero filogeneticamente mais relacionado com 
Tabela 2. Matriz de caracteres de anatomia foliar com aplicações taxonômicas em espécies brasileiras de Hypolytrum Rich.

\begin{tabular}{llllllllccccccccccc}
\hline Espécies & 1 & 2 & 3 & 4 & 5 & 6 & 7 & 8 & 9 & 10 & 11 & 12 & 13 & 14 & 15 & 16 & 17 & 18 \\
\hline H. bullatum & 0 & 0 & 1 & 0 & 1 & 1 & 0 & 0 & 0 & 1 & 1 & 0 & 1 & 2 & 1 & 1 & 1 & 0 \\
H. glaziovii & 0 & 0 & 2 & 1 & 1 & 0 & 1 & 0 & 0 & 2 & 1 & 0 & 1 & 2 & 1 & 0 & 1 & 0 \\
H. longifolium & 0 & 0 & 2 & 0 & 1 & 0 & 1 & 0 & 0 & 0 & 0 & 0 & 0 & 0 & 1 & 1 & 1 & 0 \\
H. pulchrum & 1 & 0 & 1 & 1 & 0 & 0 & 0 & 1 & 1 & 1 & 2 & 2 & 0 & 1 & 0 & 0 & 1 & 0 \\
H. rigens & 1 & 0 & 0 & 1 & 1 & 0 & 0 & 0 & 1 & 0 & 2 & 1 & 0 & 0 & 1 & 0 & 1 & 0 \\
H. schraderianum & 0 & 0 & 1 & 0 & 0 & 0 & 0 & 1 & 0 & 3 & 1 & 0 & 1 & 2 & 2 & 0 & 0 & 2 \\
H. sp. nov. & 0 & 0 & 2 & 0 & 0 & 0 & 1 & 1 & 0 & 1 & 1 & 0 & 1 & 3 & 0 & 0 & 0 & 1 \\
H. sphaerostachyum & 0 & 1 & 1 & 0 & 0 & 0 & 1 & 0 & 0 & 0 & 0 & 1 & 0 & 0 & 1 & 1 & 0 & 0 \\
H. stemonifolium & 0 & 0 & 2 & 1 & 1 & 0 & 1 & 0 & 0 & 1 & 1 & 0 & 1 & 0 & 1 & 0 & 1 & 0 \\
H. verticillatum & 0 & 0 & 2 & 1 & 1 & 0 & 1 & 0 & 0 & 2 & 1 & 0 & 1 & 2 & 1 & 0 & 0 & 1 \\
\hline
\end{tabular}

Caracteres: 1 - freqüência estomática: < 25 est.mm² $(0),>25$ est.mm² (1); 2 - distribuição estomática: hipostomática (0), anfistomática (1); 3 - nível dos estômatos: em depressão (0), nivelados (1), em elevações (2); 4 - cutícula: lisa (0), estriada (1). 5 - parede epidérmica em VF: retilínea (0), sinuosa (1); 6 - contorno em ST da face abaxial da epiderme: retilíneo (0), ondulado (1); 7 - célula epidérmica em em ST: não papilosa (0), papilosa (1); 8 - grânulos: ausentes (0), presentes (1). 9 - número de camadas de hipoderme: uma (0), duas a três (1); 10 - número de camadas de células buliformes: uma (0), duas (1), duas ou três (2), três (3); 11 - origem das células buliformes: epiderme (0), epiderme e hipoderme (1), hipoderme (2); 12 - formato da folha em ST: "W" invertido (0), "V" expandido (1), "V" expandido com reentrância (2); 13 - número de feixes vasculares na lâmina: até 40 (0), mais de 40 (1); 14 - parênquima lacunoso: ausente (0), pouco conspícuo (1), conspícuo (2), muito conspícuo (3); 15- parênquima paliçádico: indiferenciado (0), uma camada (1), duas a três camadas (2); 16 - parênquima radiado: ausente (0), tendência à estrutura Kranz (1); 17 - esclerênquima no bordo: ausente (0), presente (1); 18 - formato do bordo: truncado (0), levemente involuto (1), levemente revoluto (2).

Hypolytrum, difere deste em diversos aspectos anatômicos, confirmando o observado por Metcalfe (1971). No entanto, as cavidades de ar mencionadas por Metcalfe (1971) e Simpson (1992) para as espécies de Mapania, são regiões de parênquima aqüífero. Este eqüívoco pode ter sido devido à análise de material herborizado o que, muitas vezes, dificulta a observação.

Becquerelia é freqüentemente confundido com Hypolytrum devido à morfologia vegetativa. Individualiza-se, segundo Koyama (1967) e Metcalfe (1971), pela presença de corpos silicosos nodulares aderidos à parede das células epidérmicas e ausência de parênquima formado por células translúcidas ao longo das costelas laterais.

O emprego taxonômico e filogenético de caracteres da anatomia foliar em Hypolytrum já havia sido ressaltado anteriormente por Baas (1969), Metcalfe (1971), Koyama $(1966,1967)$ e Bruhl (1995). Os diversos autores mencionaram que, apesar da homogeneidade morfológica, apresentam caracteres diagnósticos representativos, tais como a distribuição da hipoderme e das células buliformes entre outros aspectos.

Semelhante ao presente trabalho, Metcalfe (1969) destacou, entre os caracteres que individualizam o gê- nero Hypolytrum, a ausência de corpos silicosos, a presença de hipoderme e de duas costelas laterais preenchidas por "células translúcidas" em posição exterior ao xilema. Entretanto, as "células translúcidas" foram re-interpretadas por Bruhl (1995) como sendo células parenquimáticas que também ocorrem em Paramapania, gênero que, juntamente com Hypolytrum, está posicionado na subfamília Mapanioideae.

A ausência de corpos silicosos em Hypolytrum foi diversas vezes mencionada (Koyama 1966, Metcalfe 1971). Duval-Jouve (1873) e Pfeiffer (1927), no entanto, indicaram a presença de sílica em $H$. compactum e H. floribundum, espécies paleotropicais. Dentre as espécies estudadas no presente trabalho, constatou-se a presença, em $H$. pulchrum, $H$. schraderianum e $H$. sp. nov. de grânulos provavelmente silicosos (a reação ao teste realizado para sílica foi pouco expressiva). Metcalfe (1971), Haines \& Lye (1983) e Bruhl (1995) mencionaram a ocorrência de tais corpúsculos em Bolboschoenus, Diplasia, Scleria e Fuirena, entre outros gêneros de Cyperaceae. H. rigens apresenta, muito raramente, projeções cônicas de sílica nas células epidérmicas próximas ao bordo foliar.

Tricomas tectores unicelulares e com a base 
alargada, tratados por Metcalfe (1971) e Haines \& Lye (1983) por "prickles", são amplamente difundidos entre as Cyperaceae. Nas espécies de Hypolytrum aqui estudadas, são encontrados os referidos tricomas, porém sem valor taxonômico para o grupo.

Confirmou-se também através das espécies aqui tratadas a presença de anastomoses dos feixes vasculares de segunda ordem na tribo Hypolytrae, anteriormente indicada por Metcalfe (1969).

Takeda et al. (1985), Soros \& Dengler (1998) e Soros \& Bruhl (2000) mencionaram a ocorrência de variações relacionadas à anatomia Kranz em representantes das Cyperaceae. Apesar do reduzido número de espécies de Cyperaceae que tiveram a via fotossintética tipificada, até o momento a organização Kranz (característica das plantas que realizam fotossíntese $\mathrm{C}_{4}$ ) e também as suas variações não foram detectadas entre os representantes da subfamília Mapanioideae.

Ainda assim, as espécies estudadas de Hypolytrum que apresentam parênquima radiado nas unidades vasculares de menor calibre (uma das características da anatomia Kranz), aproximam-se das tipologias ambiental e morfológica ressaltadas por Takeda et al. (1985) e Soros \& Bruhl (2000) para as Cyperaceae com anatomia Kranz. Essas espécies habitam as Florestas Atlântica (H. bullatum) e Amazônica (H. longifolium e H. sphaerostachyum).

Entre as sete espécies de Hypolytrum neotropicais estudadas por Koyama (1966), com base em material herborizado, H. glaziovii e $H$. pulchrum foram aqui tratadas e tiveram seus caracteres adequadamente confirmados no presente trabalho, excetuando a presença das células braciformes. Verificou-se ainda, que a forma do esclerênquima em ST, adotada tanto por Koyama (1966) quanto por Metcalfe (1971) como caráter representativo em Cyperaceae, é extremamente variável, portanto, de pouca confiabilidade taxonômica para o gênero. Tal variabilidade também ocorre em relação as fibras eventualmente observada no bordo foliar.

Apesar da validade como delimitador genérico, não foi possível detectar caracteres anatômico-foliares que corroborem a divisão infragenérica estabelecida por Koyama (1970). Em nível específico, no entanto, caracteres como a espessura de diferentes regiões da folha em ST, o número de feixes vasculares, a distribuição da hipoderme e a presença de corpúsculos de sílica, anteriormente empregados em gêneros como Uncinia, Fimbristylis, Cyperus e Lagenocarpus (Kukkonen 1967, Sharma \& Mehra 1972, Govindarajalu 1974, Silva 2000), revelaram-se úteis à taxonomia de Hypolytrum.

A morfologia externa, associada ao padrão de distribuição geográfica, permite reunir as espécies estuda- das em três grupos bem definidos e, com base em caracteres da anatomia foliar, é possível a individualização de cada táxon.

Entre as espécies ocorrentes nas florestas litorâneas (Floresta Atlântica e Mata de Restinga), a hipoderme em Hypolytrum sp. é formada por uma camada descontínua na face abaxial, em $H$. glaziovii por uma camada contínua em ambas as faces, enquanto que $H$. verticillatum pode apresentar duas a três camadas na face adaxial. $H$. bullatum é a única espécie estudada que possui a face abaxial da epiderme ondulada.

Hypolytrum rigens e $H$. pulchrum ocorrem exclusivamente em ambientes não florestais (Cerrado, Campos Rupestres e Campinas Amazônicas). Em ambas, a folha em ST é do tipo "V" expandido, porém $H$. pulchrum diferencia-se por apresentar uma reentrância na altura da nervura central. Além disto, as células buliformes em $H$. rigens estão distribuídas em apenas uma camada, enquanto que em $H$. pulchrum são observadas duas. Em ambos os casos são hipodérmicas.

Quanto às espécies amazônicas, $H$. stemonifolium diferencia-se das demais por não apresentar parênquima radiado e possuir duas camadas de células buliformes. H. sphaerostachyum caracteriza-se por apresentar a hipoderme interrompida por células do parênquima paliçádico enquanto que em $H$. longifolium, a hipoderme é interrompida por esclerênquima.

Hypolytrum schraderianum é a espécie mais amplamente distribuída na região Neotropical, ocorrendo tanto na Floresta Atlântica quanto na Amazônica. Distinguese das demais espécies litorâneas pela conjunção de caracteres como o esclerênquima unindo as faces adaxial e abaxial da epiderme e três camadas de células buliformes, e das amazônicas, pela existência de grânulos nas células epidérmicas, provavelmente de sílica.

Conclui-se, portanto, que os caracteres da anatomia foliar corroboram a delimitação entre os gêneros Hypolytrum e Mapania, além de permitirem o diagnóstico específico para os taxa estudados de Hypolytrum. Hypolytrum sp. nov. apresenta caracteres anatômicos que justificam o seu estabelecimento como um novo táxon. No entanto, os caracteres estudados não foram suficientes para sustentar as categorias infragenéricas estabelecidas para o gênero Hypolytrum, revelando a necessidade de que sejam reavaliadas taxonomicamente.

\section{Referências bibliográficas}

BAAS, P. 1969. Comparative leaf anatomy of Hypolytrum L.C. Rich. (Cyperaceae). Notes of Jodrell Laboratory 6:1-20. 
BRUHL, J. 1995. Sedge genera of the world: relationships and a new classification. Australian Systematic Botany 8:125-305.

CHEADLE, V. \& UHL, N. 1948. Types of vascular bundles in the Monocotyledoneae and their relation to the late metaxylem conducting elements. American Journal of Botany 35:486-496.

DUVAL-JOUVE, J. 1873. Sur une forme de cellules épidermiques que paraissent propes aux Cyperaceae. Bulletin Societé Botanique Française 20:91-95.

GOETGHEBEUR, P. 1998. Cyperaceae. In The families and genera of vascular plants (K. Kubitzki, H. Huber, P.J. Rudall, P.S. Stevens \& T. Stützel, eds.). Springer-Verlag, Berlin, v.4, p.141-190.

GOVINDARAJALU, E. 1974. The systematic anatomy of south indian Cyperaceae: Cyperus subgen. Juncellus, Cyperus subgen. Marisculus and Lipocarpha R. Br. Botanical Journal of Linnean Society 68:235-266.

HAINES, R. \& LYE, K. 1983. The sedges and rushes of East Africa. East African Natural History Society, Nairobi.

HOLMGREN, P.K., HOLMGREN, N.H. \& BAINETT, L.G. 1990. Index Herbariorum. Part 1: The Herbaria of the World. 8ed. New York Botanical Garden, New York.

JOHANSEN, D. 1940. Plant microtechnique. McGraw-Hill Book Co., New York.

KOYAMA, T. 1966. The systematic significance of leaf structure in the Cyperaceae-Mapanieae. Memoirs of the New York Botanical Garden 15:136-159.

KOYAMA, T. 1967. The systematic significance of leaf structure in the tribe Sclerieae (Cyperaceae). Memoirs of the New York Botanical Garden 16:46-70.

KOYAMA, T. 1970. The american species of the genus Hypolytrum (Cyperaceae). Darwiniana 16:49-92.

KRAUS, J. \& ARDUIN, M. 1997. Manual básico de métodos em morfologia vegetal. EDUR, Seropédica.
KUKKONEN, I. 1967. Vegetative anatomy of Uncinia. Annals of Botany 31:523-544.

METCALFE, C.R. 1969. Anatomy as an aid to classifying the Cyperaceae. American Journal of Botany 56:782-790.

METCALFE, C.R. 1971. Anatomy of the monocotyledons Cyperaceae. Clarendon Press, Oxford, v.5.

PLOWMAN, A. 1906. The comparative anatomy and phylogeny of the Cyperaceae. Annals of Botany 20:1-33.

PFEIFFER, H. 1927. Untersuchungen zur vergleichenden Anatomie der Cyperaceen. I. Die Anatomie der Blätter. Beihefte zum Botanischen Zentralblatt 44:90-176.

SAAS, J. 1951. Botanical microtechnique. The Iowa State College Press, Iowa.

SHARMA, O. \& MEHRA, P. 1972. Systematic anatomy of Fimbristylis Vahl (Cyperaceae). Botanical Gazette 133:8795.

SHEPHERD, G. 1976. The use of anatomical characteres in the infrageneric classification of Carex (Cyperaceae). Hoehnea 6:33-54.

SILVA, D. 2000. Anatomia dos órgãos vegetativos de Lagenocarpus (Cyperaceae). Tese de doutorado, Universidade de São Paulo, São Paulo.

SIMPSON, D. 1992. A revision of the genus Mapania. Royal Botanical Gardens, Kew.

SOROS, C. \& BRUHL, J. 2000. Multiple evolutionary origins of $\mathrm{C} 4$ photosynthesis in the Cyperaceae. In Monocots: Systematics and evolution (K.L. Wilson \& D. Morrison, eds.). CSIRO, Melbourne, p.629-636.

SOROS, C. \& DENGLER, N. 1998. Quantitative leaf anatomy of $\mathrm{C}_{3}$ and $\mathrm{C}_{4}$ Cyperaceae and comparisons with the Poaceae. International Journal of Plant Science 159:480491.

TAKEDA, T., UENO, O., SAMEJIMA, M. \& TAKESHI, T. 1985. An investigation of the occurrence of $C_{4}$ photosynthesis in the Cyperaceae from Australia. The Botanical Magazine, Tokyo 98:393-411. 